\title{
OPEN Patterns and processes of pathogen exposure in gray wolves across North America
}

\author{
Ellen E. Brandell ${ }^{1 凶}$, Paul C. Cross ${ }^{2}$, Meggan E. Craft ${ }^{3}$, Douglas W. Smith ${ }^{4}$, Edward J. Dubovi ${ }^{5}$, \\ Marie L. J. Gilbertson ${ }^{6}$, Tyler Wheeldon ${ }^{7}$, John A. Stephenson ${ }^{8}$, Shannon Barber-Meyer ${ }^{9}$, \\ Bridget L. Borg ${ }^{10}$, Mathew Sorum ${ }^{11}$, Daniel R. Stahler ${ }^{4}$, Allicia Kelly ${ }^{12}$, Morgan Anderson ${ }^{13}$, \\ H. Dean Cluff ${ }^{14}$, Daniel R. MacNulty ${ }^{15}$, Dominique E. Watts ${ }^{16}$, Gretchen H. Roffler ${ }^{17}$, \\ Helen Schwantje ${ }^{18}$, Mark Hebblewhite ${ }^{19}$, Kimberlee Beckmen ${ }^{20}$, Heather Fenton ${ }^{14,21}$ \& \\ Peter J. Hudson ${ }^{1}$
}

The presence of many pathogens varies in a predictable manner with latitude, with infections decreasing from the equator towards the poles. We investigated the geographic trends of pathogens infecting a widely distributed carnivore: the gray wolf (Canis lupus). Specifically, we investigated which variables best explain and predict geographic trends in seroprevalence across North American wolf populations and the implications of the underlying mechanisms. We compiled a large serological dataset of nearly 2000 wolves from 17 study areas, spanning $80^{\circ}$ longitude and $50^{\circ}$ latitude. Generalized linear mixed models were constructed to predict the probability of seropositivity of four important pathogens: canine adenovirus, herpesvirus, parvovirus, and distemper virus-and two parasites: Neospora caninum and Toxoplasma gondii. Canine adenovirus and herpesvirus were the most widely distributed pathogens, whereas $N$. caninum was relatively uncommon. Canine parvovirus and distemper had high annual variation, with western populations experiencing more frequent outbreaks than eastern populations. Seroprevalence of all infections increased as wolves aged, and denser wolf populations had a greater risk of exposure. Probability of exposure was positively correlated with human density, suggesting that dogs and synanthropic animals may be important pathogen reservoirs. Pathogen exposure did not appear to follow a latitudinal gradient, with the exception of $N$. caninum. Instead, clustered study areas were more similar: wolves from the Great Lakes region had

${ }^{1}$ Center for Infectious Disease Dynamics, Department of Biology, Huck Institutes of the Life Sciences, Pennsylvania State University, University Park, PA 16802, USA. ²U.S. Geological Survey, Northern Rocky Mountain Science Center, Bozeman, MT 59715, USA. ${ }^{3}$ Department of Ecology, Evolution, and Behavior, University of Minnesota, Saint Paul, MN 55108, USA. ${ }^{4}$ Yellowstone Center for Resources, Wolf Project, P.O. Box 168, Yellowstone National Park, WY 82190, USA. ${ }^{5}$ Animal Health Diagnostic Center, College of Veterinary Medicine, Cornell University, Ithaca, NY 14850, USA. ${ }^{6}$ Department of Veterinary Population Medicine, University of Minnesota, Saint Paul, MN 55108, USA. ${ }^{7}$ Ontario Ministry of Natural Resources and Forestry, Trent University, 2140 East Bank Drive, Peterborough, ON K9L 1Z8, Canada. ${ }^{8}$ Grand Teton National Park, P.O. Drawer 170, Moose, WY 83012, USA. ${ }^{9}$ U.S. Geological Survey, Northern Prairie Wildlife Research Center, 8711 37th St. SE, Jamestown, ND 58401, USA. ${ }^{10}$ Denali National Park and Preserve, Central Alaska Inventory and Monitoring Network, P.O. Box 9, Denali Park, AK 99755, USA. ${ }^{11}$ Yukon-Charley Rivers National Preserve, Central Alaska Inventory and Monitoring Network, 4175 Geist Road, Fairbanks, AK 99709, USA. ${ }^{12}$ Department of Environment and Natural Resources, Government of the Northwest Territories, P.O. Box 900, Fort Smith, NT XOE OPO, Canada. ${ }^{13}$ British Columbia Ministry of Forests, Lands, Natural Resource Operations and Rural Development, 2000 South Ospika Blvd., Prince George, BC V2N 4W5, Canada. ${ }^{14}$ Environment and Natural Resources, Government of the Northwest Territories, North Slave Region, NT X1A 2P9, Canada. ${ }^{15}$ Department of Wildland Resources, Utah State University, Logan, UT 84322, USA. ${ }^{16}$ U.S. Fish and Wildlife Service, Kenai National Wildlife Refuge, P.O. 2139, Soldotna, AK 99669, USA. ${ }^{17}$ Division of Wildlife Conservation, Alaska Department of Fish and Game, 802 3rd Street, Douglas, AK 99824, USA. ${ }^{18}$ Wildlife and Habitat Branch, British Columbia Ministry of Forests, Lands, Natural Resource Operations and Rural Development, 2080 Labieux Road, Nanaimo, BC V9T 6J9, Canada. ${ }^{19}$ Wildlife Biology Program, Department of Ecosystem and Conservation Sciences, Franke College of Forestry and Conservation, University of Montana, Missoula, MT 59812, USA. ${ }^{20}$ Division of Wildlife Conservation, Dept of Fish and Game, 1300 College Road, Fairbanks, AK 99701, USA. ${ }^{21}$ Ross University School of Veterinary Medicine, Basseterre, West Indies KN-03, St. Kitts and Nevis. ${ }^{\square}$ email: ebrandell08@gmail.com 
lower odds of exposure to the viruses, but higher odds of exposure to $N$. caninum and T. gondii; the opposite was true for wolves from the central Rocky Mountains. Overall, mechanistic predictors were more informative of seroprevalence trends than latitude and longitude. Individual host characteristics as well as inherent features of ecosystems determined pathogen exposure risk on a large scale. This work emphasizes the importance of biogeographic wildlife surveillance, and we expound upon avenues of future research of cross-species transmission, spillover, and spatial variation in pathogen infection.

The prevalence and dynamics of infectious diseases can vary spatially across the distribution of their hosts depending on host demographics, host contact patterns, and pathogen survival. For example, Ferrari et al. ${ }^{1}$ showed how the cyclic dynamics of measles varies with human birth rate and seasonality. In a similar manner, Hudson et al. ${ }^{2}$ showed how the oscillations of red grouse (Lagopus lagopus scotica) abundance, driven by a caecal nematode, varied geographically according to the host growth rate and parasite transmission rate, and this drives longer cycle periods with increasing latitude. Pathogens that infect multiple host species may be more common at lower latitudes when this corresponds with increased numbers of host species or individuals. For example, parasites with complex life cycles that depend on the presence of intermediate hosts ${ }^{3,4}$ and seasonal aggregations, which vary with climate, can increase transmission and drive outbreaks ${ }^{5}$. In this paper we addressed the question: How does pathogen seroprevalence in gray wolves (Canis lupus) vary across North America and does geography provide a suitable proxy?

Generally, human and wildlife pathogen pressures (e.g., parasite burden, richness, prevalence) decline as latitude increases ${ }^{6-11}$ (i.e., towards the poles). Latitude is a proxy for other variables that predictably vary over space and affect pathogen transmission, which may be a function of pathogen survival or host density. For example, latitude can be used to describe the climate envelope for chytrid fungus, where higher latitudes (e.g., cooler temperatures, higher rainfall) are more optimal for fungal survival than lower latitudes. Consequently, chytrid infection intensity is significantly higher at higher latitudes ${ }^{12}$. Understanding the mechanisms driving transmission provides a deeper understanding of host-pathogen dynamics but requires detailed datasets that are often challenging to collect. Here, we assess how well geography alone can explain the observed variation in seroprevalence, and contrast this with variables that may confer a mechanistic understanding of pathogen exposure at individual and population levels, such as wolf and human densities, wolf age, sex, coat color, pack size, or habitat quality (Table 2).

In North America, wolves suffer from both enzootic and epizootic pathogens that can result in chronic disease or acute outbreaks, causing morbidity, mortality, and reduced recruitment ${ }^{13-16}$. Patterns of seroprevalence across wolf populations have not been comprehensively explored, but individual studies have shown notable differences in seroprevalence. For instance, Neospora caninum antibodies were not detected in any wolves sampled from the Alaska Peninsula ${ }^{17}$, while $66 \%$ of adult wolves in northeastern Minnesota were seropositive ${ }^{18}$. This has constrained our understanding about what pathogens we can expect wolves to be exposed to and at what frequency. To investigate the drivers of pathogen exposure, we compiled a serological dataset of North American wolves spanning 17 study areas across $80^{\circ}$ of longitude, from the Alaska Peninsula in the west to Ontario in the east, and $50^{\circ}$ of latitude, from Ellesmere Island in the north to Arizona and New Mexico in the south (Fig. 1). Wolf sera were tested for antibodies to four viruses: canine adenovirus-1 (i.e., adenovirus), canine parvovirus-2 (i.e., parvovirus), canine distemper virus (i.e., distemper), canine herpesvirus (i.e., herpesvirus), and two protozoa: Neospora caninum, and Toxoplasma gondii (Table 1).

For directly transmitted pathogens (e.g., adenovirus, herpesvirus, parvovirus), contact rate (i.e., population density) determines transmission rates, and consequently pathogen seroprevalence and outbreak size ${ }^{19}$. Population density is also important for pathogens with environmental transmission (e.g., parvovirus) such that environmental reservoirs and contamination may accumulate more quickly at higher host densities ${ }^{20}$. The presence and population densities of sympatric reservoir hosts, including synanthropic animals, is also important for the dynamics of multi-host viruses (e.g., canine distemper, T. gondii) ${ }^{21-26}$, as well as parasites with intermediate hosts (e.g., Neospora caninum $)^{27}$. Our large-scale dataset captures natural variation in human density, wolf density (e.g., population density, pack size, pack density), host presence (i.e., habitat quality), and primary prey, allowing us to examine their importance (Table 2, Fig. 2).

In addition to larger scale processes, individual characteristics also play a role in wolf pathogen dynamics. North American wolves generally display two coat color phenotypes, black and gray, that vary latitudinally ${ }^{28}$. The black genotype is important for mounting immune response ${ }^{29}$, and thus it has been hypothesized that the black color is maintained via selection from pathogen pressure ${ }^{30,31}$. This leads us to predict that black wolves are more likely to survive an exposure and test positive. Other individual traits, such as age and sex, may also influence pathogen exposure and should also be considered. Specifically, males tend to have higher pathogen prevalence than females due to physiology (e.g., sex and stress hormones) and behavior (e.g., contact patterns), and older individuals have had more time to be exposed to infectious diseases, thus tend to have elevated seroprevalence ${ }^{32-36}$.

In wildlife diseases literature, there is a lack of broad scale assessments in exposure trends that also include the animal's ecology as mechanisms. We tested how well a suite of variables conferring mechanisms (Table 2) explained and predicted differences in probability of pathogen exposure across North American wolf populations, compared with latitude and longitude alone. 


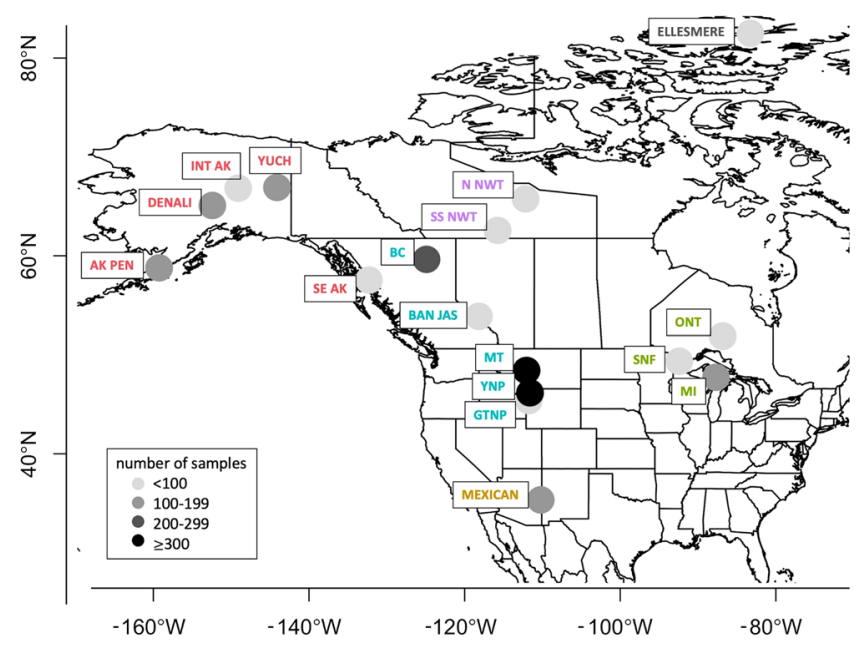

Figure 1. A map ${ }^{38}$ depicting where wolves were sampled across North America for pathogen and parasite testing, and relative sample size from each study area is shown in shades of gray (increasingly dark gray = increasing sample size $)^{39}$. Each study area is identified as follows: Alaska Peninsula (AK PEN), Denali National Park (DENALI), central-eastern Alaska (INT AK), Yukon-Charley Rivers National Preserve (YUCH), Ellesmere Island (ELLESMERE), North Slave Northwest Territories (N NWT), South Slave Northwest Territories (SS NWT), British Columbia (BC), southeastern Alaska (SE AK), Banff and Jasper National Parks (BAN JAS), Montana (MT), Yellowstone National Park (YNP), Grand Teton National Park (GTNP), Mexican wolves (MEXICAN), Ontario (ONT), Superior National Forest (SNF), and the Upper Peninsula of Michigan (MI). Study area labels were colored by region: High Arctic (gray), Subarctic (purple), Alaska (red), central Rocky Mountains (turquoise), Great Lakes (green), and Mexican (gold), and displayed as a circle with a 200-km radius.

\begin{tabular}{|c|c|c|c|c|}
\hline Pathogen & Transmission route & Alternative Hosts & Symptoms / effects & Population consequences \\
\hline Canine adenovirus & $\begin{array}{l}\text { Direct via respiratory secretions; } \\
\text { fecal-oral }\end{array}$ & None & Fever, liver inflammation & Mild \\
\hline Canine distemper virus & $\begin{array}{l}\text { Direct via respiratory droplets/secre- } \\
\text { tions; airborne }\end{array}$ & $\begin{array}{l}\text { Carnivores-grizzly (Ursus arctos) and } \\
\text { black bears (Ursus americanus), cougars } \\
\text { (Puma concolor), lynx (Lynx canaden- } \\
\text { sis), coyotes (Canis latrans), raccoons } \\
\text { (Procyon lotor), skunks (Mephitis } \\
\text { mephitis), domestic dogs (Canis lupus } \\
\text { familiaris) }\end{array}$ & $\begin{array}{l}\text { Enamel hypoplasia, seizures, death- } \\
\text { mostly affects pups or naive, immuno- } \\
\text { compromised adults }\end{array}$ & Severe (albeit acute) \\
\hline Canine herpesvirus & $\begin{array}{l}\text { Vertical; sexual; direct via respiratory } \\
\text { droplets/ secretions }\end{array}$ & None & $\begin{array}{l}\text { Adult females: abortion; pups: lethargy, } \\
\text { sudden death }\end{array}$ & Mild \\
\hline Canine parvovirus & Fecal-oral & Domestic dogs & Pups: diarrhea, lethargy, death & Moderate (but variable) \\
\hline Neospora caninum & $\begin{array}{l}\text { Ingesting infected tissue (definitive) or } \\
\text { oocysts (intermediate); vertical }\end{array}$ & $\begin{array}{l}\text { Intermediate: Ungulates } \\
\text { Definitive: canids-coyotes, foxes } \\
\text { (Vulpes vulpes) }\end{array}$ & $\begin{array}{l}\text { Muscle weakness, tremors, loss of } \\
\text { coordination }\end{array}$ & Mild \\
\hline Toxoplasma gondii & $\begin{array}{l}\text { Ingesting infected tissue or oocysts; } \\
\text { vertical }\end{array}$ & $\begin{array}{l}\text { Intermediate: Warm-blooded animals } \\
\text { Definitive: felids-cougars, lynx, bobcat } \\
\text { (Lynx rufus), domestic cats (Felis catus) }\end{array}$ & Increased aggression and risk-taking & Mild \\
\hline
\end{tabular}

Table 1. A list of wolf pathogens that were examined for populations sampled across North America (Fig. 1) and their characteristics ${ }^{37}$. 'Alternative hosts' refers to hosts other than wolves that occur within the study areas that we expect to be important in transmitting pathogens to wolves. 'Population consequences' describes the known or expected severity of these pathogen infections on wolf population size or growth rate (minimal, moderate, severe).

\section{Materials and methods}

Serology dataset. We aimed to compile a serological dataset from wolf populations across North America. We collaborated with wildlife professionals across the continent and attempted to obtain samples from a variety of ecosystems. While our dataset is expansive, there are gaps for two primary reasons: (1) wolves were not sampled or intensively studied in many areas, and (2) wolves do not occupy much of their historic North American range, especially in the south, thus they are absent from much of the United States. At a broad scale, our dataset is a fair representation of where wolves presently occur and are studied across North America.

All wolf samples analyzed for this study were previously collected by wildlife professionals within each study area. No wolf was captured or handled for the purposes of this study. Samples previously collected from livecaptured wolves were handled and sampled according to the American Society of Mammalogists (Sikes et al. 


\begin{tabular}{|c|c|c|}
\hline Variable name & Description & Rationale for inclusion/prediction \\
\hline Latitude $^{+}$ & Latitude at study area centroid & $\begin{array}{l}\text { Latitude may capture geographic variation in pathogen infections; we predicted } \\
\text { that seroprevalence decreases as latitude increases. }\end{array}$ \\
\hline Longitude $^{+}$ & Longitude at study area centroid & Longitude may capture geographic variation in pathogen infections. \\
\hline Age class ${ }^{*+}$ & Estimate of wolf age class: pup $(<1)$, subadult $(1-2)$, and adult $(\geq 3)$ & $\begin{array}{l}\text { As individuals age, they have more time to be exposed to pathogens, thus older } \\
\text { wolves will have higher seroprevalence. Age category is less error-prone than } \\
\text { numerical age estimates. }\end{array}$ \\
\hline Year $^{*}$ & Biological year, birth month $=$ first month & $\begin{array}{l}\text { Pathogen exposure may be predictable by year (i.e., endemics), or unpredict- } \\
\text { able (i.e., epidemics). }\end{array}$ \\
\hline Study area* & Study area abbreviation & $\begin{array}{l}\text { Study area may describe variation in pathogen exposure, not accounted for by } \\
\text { other variables. }\end{array}$ \\
\hline Habitat quality* & Index for habitat quality based on land cover type and topography & $\begin{array}{l}\text { A continuous estimate of the habitat quality of the study area, this covariate } \\
\text { considers habitat characteristics that carnivores, especially wolves, positively } \\
\text { select. This is a proxy for the presence of sympatric carnivore hosts. Prediction: } \\
\text { seroprevalence increases with habitat quality. }\end{array}$ \\
\hline Human density* & Number of people/1000-km² & $\begin{array}{l}\text { Provides information about how urban the area is, and thus the potential for } \\
\text { contact between unvaccinated dogs or synanthropic species (e.g., rodents, coy- } \\
\text { otes, raccoons, skunks, cats) and wolves. Prediction: seroprevalence increases } \\
\text { with human density. }\end{array}$ \\
\hline Wolf density* & $\begin{array}{l}\text { Number of wolves } / 1000-\mathrm{km}^{2} ; \text { mean annual density results in one estimate per } \\
\text { study area }\end{array}$ & $\begin{array}{l}\text { Population density is related to direct transmission rates and environmental } \\
\text { contamination. Prediction: seroprevalence increases with wolf density. }\end{array}$ \\
\hline Pack size ${ }^{*}$ & Mean annual pack size; one estimate per study area & $\begin{array}{l}\text { This tells us about the daily contacts of a wolf, which differs from contact rate at } \\
\text { the population-level. Prediction: seroprevalence increases with pack size. }\end{array}$ \\
\hline Sex* & Male or Female & $\begin{array}{l}\text { There is evidence that males have higher pathogen prevalence than females } \\
\text { across many taxa and pathogens-we predict males have higher seroprevalence }\end{array}$ \\
\hline Coat color ${ }^{*}$ & Gray or Black & $\begin{array}{l}\text { The locus that confers black coat color in wolves is linked to beta-defensin } \\
\text { genes, which increases the responsiveness of the innate immune system. We } \\
\text { assume gray=missing k-locus, black=presence of k-locus. Prediction: black } \\
\text { wolves have higher seroprevalence. }\end{array}$ \\
\hline Age & Estimate of wolf age; integer to two decimal places & $\begin{array}{l}\text { As individuals age, they have more time to be exposed to pathogens, thus we } \\
\text { predicted older wolves have higher seroprevalence. }\end{array}$ \\
\hline Social status & Breeder or non-breeder & $\begin{array}{l}\text { Breeders typically have higher stress levels and energetic demands than non- } \\
\text { breeders, which we predict increases seroprevalence. }\end{array}$ \\
\hline Prey species & Top two primary prey species & $\begin{array}{l}\text { N. caninum or T. gondii may be more prevalent in different intermediate hosts. } \\
\text { Prediction: seroprevalence is higher where white-tailed deer are a primary prey } \\
\text { species. }\end{array}$ \\
\hline Pack membership & Name of the pack the wolf was a member of when sampled & $\begin{array}{l}\text { There may be heterogeneities in pathogen exposure based on pack member- } \\
\text { ship. }\end{array}$ \\
\hline Pack density & $\begin{array}{l}\text { Number of packs } / 1000-\mathrm{km}^{2} \text {; mean annual density results in one estimate per } \\
\text { study area }\end{array}$ & $\begin{array}{l}\text { Contact among wolves from different packs is likely influenced by the number } \\
\text { of packs in the population. Prediction: seroprevalence increases with pack } \\
\text { density. }\end{array}$ \\
\hline
\end{tabular}

Table 2. A list of variables considered for inclusion in generalized linear mixed models predicting pathogen and parasite exposure. Variable descriptions and rationales or predictions are provided; a indicates the variable was included in the final complete model, $\mathrm{a}^{+}$indicates the variable was included in the geographic model.

2016), or similar guidelines, and approved by the appropriate institutions-see Supplementary Table S5 for specific approval and permits associated with samples included in our database. All samples from the northern Northwest Territories and about half from Ellesmere Island, Nunavut, were air dried, blood-soaked filter paper, and almost all other samples were serum collected from the cephalic or saphenous vein during live capture. We leveraged stored (i.e., frozen at $-20^{\circ}$ to $-80^{\circ}$ Celsius) samples for this study and, where needed, we coordinated with local wildlife professionals to ship serum to the Animal Health Diagnostic Center at Cornell University (Ithaca, NY, USA) where samples were screened for antibodies to the six pathogens of interest.

We screened wolf samples from 13 of the 17 study areas, and we used previously published serological results for the remaining 4 study areas (Supplementary Table S2). Previously published datasets included in our analyses were: Mexican ${ }^{40}$, Banff and Jasper National Parks ${ }^{41}$, Alaska Peninsula ${ }^{17}$, and a portion of the samples from Superior National Forest ${ }^{18}$. Here we discuss how samples were analyzed at the Animal Health Diagnostic Center at Cornell University, which comprised about $80 \%$ of our dataset (see Supplementary Table S3 for other testing information). Virus neutralization assays were performed to detect antibodies to canine adenovirus, distemper virus, and herpesvirus; hemagglutination inhibition assays were used for parvovirus; indirect fluorescent assays were used for N. caninum; enzyme-linked immunosorbent assay or monocyte activation tests were used for $T$. gondii. All assays provided titer values except for the indirect fluorescent and enzyme-linked immunosorbent assays, which provided a positive, negative, or suspect/equivocal result. Sample collection and test methods for the previously published samples were identical or equivalent to methods implemented for the other 13 study areas, thus are directly comparable (Supplementary Tables S2, S3).

The response variable in our models was a binary variable representing previous exposure (1), i.e., seropositive result, or not (0), i.e., seronegative result. A result was seropositive when the titer dilution was equal or greater than the standard titer cutoff provided by the assay manufacturer (Supplementary Table S3), or if the assay was 

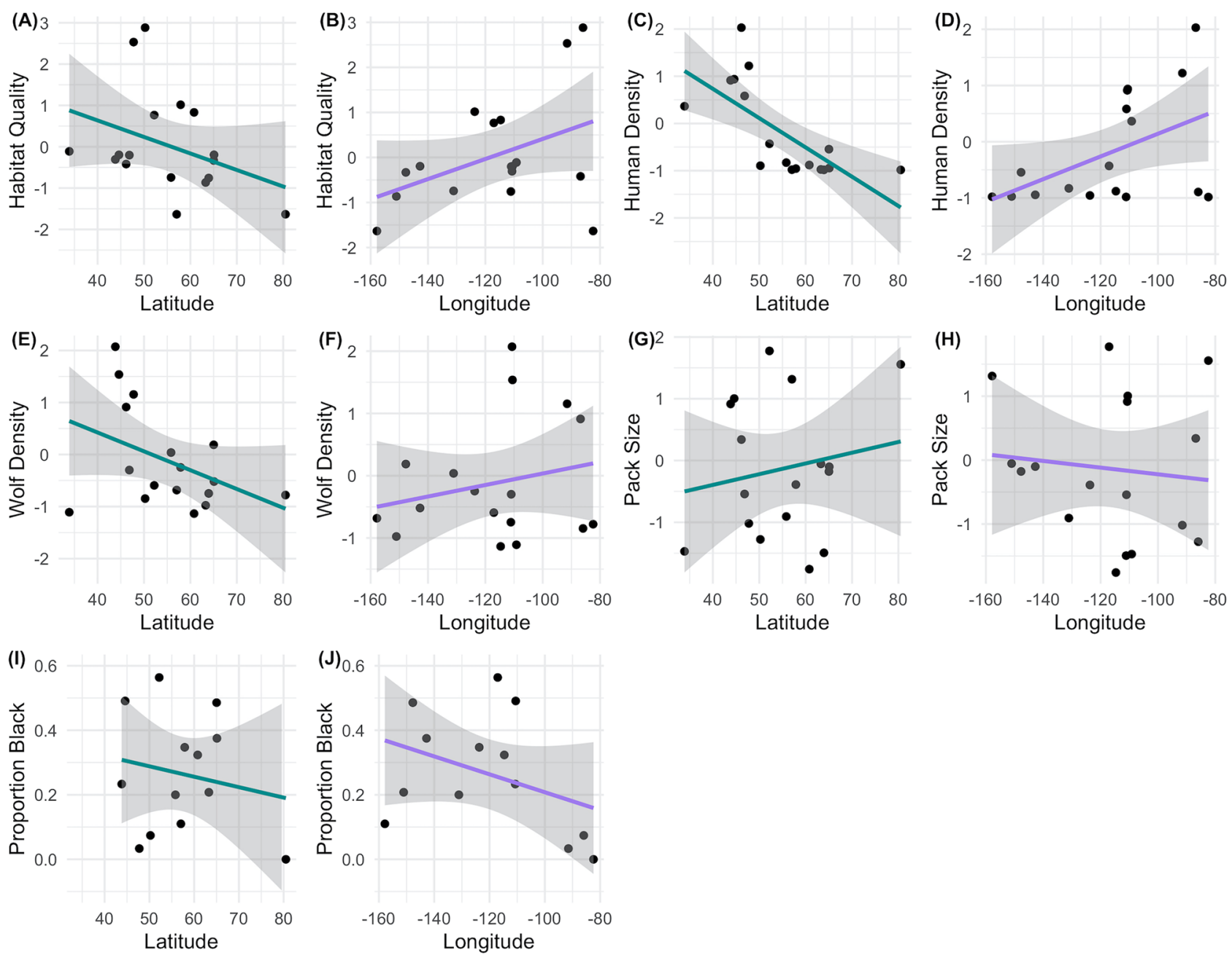

Figure 2. The effect of latitude (teal lines) and longitude (purple lines) on selected standardized, continuous predictor variables that were included in the generalized linear mixed models ${ }^{39}:(\mathbf{A}, \mathbf{B})$ habitat quality, $(\mathbf{C}, \mathbf{D})$ human density, (E,F) wolf density, $(\mathbf{G}, \mathbf{H})$ pack size, as well as $(\mathbf{I}, \mathbf{J})$ proportion of black wolves (for $\mathbf{I}, \mathbf{J}$, note that MI, MT, and N NWT were removed due to lack of coat color data; MEXICAN was removed as Canis lupus baileyi does not present a black phenotype). Gray polygons are $95 \%$ confidence intervals around univariate regression lines.

positive/suspect (suspect comprised $\sim 3 \%$ of the total dataset). As such, we assumed that serological assays were considered to be perfect, which is unlikely to be true. To address this, we assessed population seroprevalence using standard and conservative titer cutoffs; the standard cutoff is the lab-recommended value (Supplementary Table S3), and the conservative cutoff is one dilution above the standard cutoff. We found that pathogen prevalence was minimally affected by titer cutoff and we do not believe that this affected our results (Supplementary Fig. S1). Therefore, we present results using a standard titer cutoff specific to each assay and sample type. Note too that only individuals that survived an exposure were available to be sampled for serological analyses, thus lack of antibody detection may mean that the pathogen does not exist in that study area, or alternatively, that it caused high mortality locally and was not detected.

Model construction. We constructed and analyzed models predicting the probability that a wolf was exposed to a given pathogen using R v3.6.3 $3^{39}$. We tested how well geography (i.e., latitude and longitude) explained and predicted pathogen exposure compared with mechanistic predictor variables. Two models were constructed for each pathogen: a complete model and a geographic model (Eq. 1). The geographic model, which acted as a null/uninformative model, contained latitude and longitude, and controlled for the effect of age. The complete model contained selected predictor variables (Table 2). Both models included random effects (generalized linear mixed model, 'GLMM'). Models were fit with a complementary-log-log link and a Bernoulli error distribution using the function glmer in the package $l m e 4^{42}$. In the complete model, year and study area were both considered as random effects, where year was nested within study area because we posited that the effect of year differed within each study area. Nesting year within study area gave us a random effect for study area alone, as well as study area ${ }^{*}$ ear. Study area was the only random effect considered in the geographic model. The form of our GLMMs was: 


$$
\begin{gathered}
Y_{i j k}=\operatorname{Bernoulli}\left(p_{i j k}\right) \\
f\left(p_{i j k}\right)=\beta_{0}+\beta_{1} x_{1 i j k}+\cdots+\beta_{n} x_{n i j k}+\alpha_{j}+\gamma_{j k}+\varepsilon_{i} \\
\alpha_{j} \sim \operatorname{Normal}\left(0, \sigma^{2}\right) \\
\gamma_{j k} \sim \operatorname{Normal}\left(0, \sigma^{2}\right)
\end{gathered}
$$

where $Y_{i j k}$ is the seropositive result for the $n_{j k}$ trial from the $i$ th individual from the $j$ th study area in year $k$; $p_{i j k}$ is the probability of exposure from the $i$ th individual from the $j$ th study area in year $k$; $x_{n i j k}$ is the $i$ th value of the $j$ th study area in the $k$ th year for the $n$th predictor; $\beta_{n}$ are the estimated predictor coefficients; $\alpha_{j}$ is the study area-specific effect; $\gamma_{j k}$ is the effect of year within that study area; $\varepsilon_{i}$ is the remaining error in seropositivity. The year effects, including $\gamma_{j k}$, did not appear in the geographic model. The link function $(f)$ applied is the complementary-log-log.

All metadata were collected specifically for this project such that we determined our hypotheses $a$ priori ${ }^{43}$ (Table 2, Supplementary Table S1). All variables considered were expected to influence pathogen exposure. Table 2 displays variables considered for inclusion in the models, descriptions, and rationales or predictions. Each sample was assumed to be unique, given that $<7 \%$ of the data were recollared wolves. If multiple age estimates were given (e.g., 3 or 4 years old), we randomly selected one age estimate. Some variables were removed prior to model building due to lack of sufficient data, including pack membership, social status, and pack density (Supplementary Table S4). Prey species was not included because primary prey species were too similar across study areas (e.g., a combination of elk, deer spp., moose, caribou), and after exploratory plotting, did not appear to provide additional information above study area and habitat quality. Prey species also are likely reflected in wolf density and pack size ${ }^{44-47}$. We included age class instead of age in our models because age was based on tooth wear and body size, and is an error-prone estimate especially for older ages ${ }^{48}$. We used coat color as a proxy for the presence of the K-locus allele, which is supported by Anderson et al. ${ }^{28}$ who found that $>98 \%$ of wolves from Yellowstone and western Canada classified as 'black' did indeed have the K-locus genotype.

We also considered wolf density, pack size, human density, habitat quality, and sex as potentially important predictors of pathogen exposure (Table 2). Wolves were counted in all study areas, including annual population counts and pack size estimates. These data were typically collected during aerial or ground tracking surveys in the winter. If more than one estimate was available per year within a study area, which was common for pack sizes, they were averaged to create one annual wolf density (number of wolves $/ 1000-\mathrm{km}^{2} /$ year) and one annual mean pack size (mean number of wolves/pack/year) value per study area. To estimate human density and habitat quality, we first had to determine how large of an area should be considered, as most areas did not have clearly defined boundaries or isolated wolf populations. We considered a range of area sizes (radius $50-\mathrm{km}$ to $300-\mathrm{km}$ from study area centroids) and selected a $200-\mathrm{km}$ radius because human density and habitat quality were less variable in comparison with small or large radii, and it is more congruent with wolf dispersal distance ${ }^{49,50}$. Human density was considered to be the number of people per $1000-\mathrm{km}^{251}$, and was used as a proxy for the presence of unvaccinated dogs and synanthropic animals ${ }^{52}$. Habitat quality was a proxy for the presence of carnivore hosts, and was a continuous variable calculated as the product of: percent forest cover ${ }^{53}$, percent area with slope $\leq 20^{\circ}$ ${ }^{54}$, and density of hard edges (e.g., cutblocks, pipeline cuts, forest edges; R package landscapemetrics ${ }^{55}$ ). These habitat characteristics were selected because they were considered positive predictors of carnivore presence, such as grizzly bears, lynx, bobcat, coyotes, with a focus on wolves ${ }^{56-68}$. While this proxy for carnivore presence is imperfect as carnivore distributions varied over our sampling distribution, and carnivores may select for different landscape features at different scales, it captures important features where wolves and other carnivores may interact, and therefore where cross-species pathogen transmission may occur. Finally, sex (male or female) was recorded during captures.

Before building the complete model, all variables were screened for collinearity using Spearman's correlation coefficient $(\rho)$. Human density and wolf density were highly correlated $(\rho=0.62$; Supplementary Fig. S3, S4) and thus were not included in the same model; however, as we were interested in the effects of both wolf and human density on pathogen dynamics, we ran the complete model both ways (i.e., with either wolf density or human density). All variables other than latitude and longitude were retained (i.e., correlation $<0.4)$. Latitude was highly correlated with human density $(\rho=-0.79)$ and moderately correlated with wolf density $(\rho=-0.36)$ and habitat quality $(\rho=-0.33$, Fig. $2, S 3)$. Longitude was moderately correlated with human density $(\rho=0.37)$, habitat quality $(\rho=0.30)$, and proportion of black wolves $(\rho=-0.33$, Fig. 2, Supplementary Fig. S3). Our models were as follows (note that the divider between year and study area denotes the nested structure study area + study area ${ }^{\star}$ ear):

Complete model.

$$
\begin{aligned}
\text { Probability (exposure) }) & \sim \text { wolf density or human density }+ \text { habitat type } \\
& + \text { pack size }+ \text { age class }+ \text { sex }+ \text { color }+(\text { study area } \mid \text { year })
\end{aligned}
$$

Geographic model. 


$$
\text { Probability (exposure) } \sim \text { latitude + longitude + age class }+ \text { study area }
$$

Continuous variables were standardized prior to model implementation (subtract the variable mean and divide by the standard deviation, Gelman and $\mathrm{Hill}^{69}$, Menard $\left.{ }^{70}\right)$. This centers all variables $(\mathrm{mean}=0)$, and deviations from the mean are represented in standard deviations. Standardizing puts all continuous variables on the same scale, allowing for direct comparisons and simplifying interpretation. All models converged using the bobyqa optimizer.

Model evaluation. Models were evaluated by root mean square error (RMSE) and area under the receiveroperator curve (AUC). RMSE and AUC provide different, important model evaluation. RMSE is a measure of model fit as it calculates the error between the observed data and the fitted model, whereas AUC provides a measure of the classification accuracy of the model; both criteria use model fixed effects. To calculate AUC, the false positive rate $(1-$ specificity) is plotted against the true-positive rate (sensitivity); AUC $=0.5$ indicates no discrimination, AUC $>0.5$ indicates that the true positive rate is higher than the false-positive rate, and AUC $>0.8$ indicates excellent discrimination ${ }^{71}$. We compared the testing set and training set RMSE and AUC using four-fold cross validation ${ }^{72}$ (see Supplementary Information for training and testing group information). Supplementary Figure S5 and Table S6 display the mean RMSE and AUC across the four datasets (training and testing) per pathogen and model.

Model fit assessments included: training and testing set RMSE and AUC estimates, pseudo-R2 values (calculated with fixed effects only), Maximum Likelihood estimator convergence, and p-values (i.e., hypothesis testing, Table 2). Predictor variables were considered statistically significant at an alpha value of $\leq 0.05$. The geographic and complete models, parameter estimation, and their evaluations used all (non-missing) data.

\section{Results}

Dataset. We sampled 1839 wolves from 17 study areas to comprise the final dataset, with 134 wolves resampled, totaling 1973 rows of data. The mean number of samples per study area was 116 (95\% confidence interval [CI] 90-142), ranging from 10 (SE AK) to 383 (YNP), but most study areas had between 50 and 150 samples. Most study areas were sampled for 10 years $(95 \%$ CI 8.5-11.8, range $=2-25)$ and, on average, 12 wolves were sampled per year (95\% CI 11-13). Collectively, study areas had a mean wolf density of 13 wolves $/ 1000-\mathrm{km}^{2}(95 \%$ CI $11-16$, range $=3.4-34.0)$ and a mean of 6.3 wolves per pack (95\% CI 5.8-6.8, range $=3.7-9.6)$. Habitat quality with respect to the presence of carnivore hosts was similar in most study areas, although a few populations stood out as low quality (AK PEN, Ellesmere Island), and others as high quality (ONT, SNF). Human density was more variable: some study areas had $<11$ people $/ 1000-\mathrm{km}^{2}$ (AK PEN, Ellesmere, N NWT) and others had $>3000$ people/1000-km² (MI, SNF, YNP, GTNP, MT), with a mean of $\sim 1600$ people $/ 1000-\mathrm{km}^{2}$.

Most wolves sampled were adults (44\%), and pups and subadults were equally sampled (28\% each). Males and females were nearly equally sampled ( $52 \%$ and $48 \%$, respectively), and there were more than twice as many gray wolves sampled $(70 \%)$ as black wolves (30\%). Some metadata were missing, in particular coat color, and missing information tended to be grouped by population (Supplementary Table S4).

Adenovirus was the most widespread and prevalent pathogen (mean seroprevalence $86.2 \%$, sd $=8.0 \%$, range $=73.5-100 \%$ ), followed by herpesvirus (mean seroprevalence $79.5 \%$, sd $=11.3 \%$, range $=57.1-94.3 \%$, Fig. 3). N. caninum was the least common pathogen (mean seroprevalence $24.8 \%$, sd $=24.4 \%$, range $=0-74.7 \%$, Fig. 3), and T. gondii was moderately prevalent across study areas (mean seroprevalence $51.5 \%$, sd $=20.5 \%$, range $=26.9-87.6 \%$, Fig. 3 ). Distemper virus was relatively uncommon (mean seroprevalence $22.7 \%$, $s d=18.0 \%$, range $=0-55.6 \%$, Fig. 3 ), but as an epizootic virus, overall seroprevalence is a poor representation of viral pressure or dynamics. We identified clear peaks in distemper seroprevalence in most populations that were sampled for at least five consecutive years (Supplementary Fig. S2). Evidence of exposure to parvovirus was the most variable (mean seroprevalence $73.8 \%$, sd $=25.0 \%$, range $=10.0-100 \%$ ). Interestingly, parvovirus tended to be enzootic (e.g., BAN JAS, GTNP, MT, SNF, YNP) or common but variable (e.g., BC, DENALI, MEXICAN, MI, SS NWT, YUCH), but was uncommon in some study areas (e.g., AK PEN, SE AK), or patterns were unclear (e.g., INT AK, ELLES, N NWT, ONT, Fig. 3, Supplementary Fig. S2).

Model results. The coefficient estimates $(\beta)$ for latitude were negative for all pathogens except adenovirus and distemper where $\beta \sim 0$. However, latitude was only a statistically significant predictor of $N$. caninum exposure such that the probability of exposure to N. caninum decreased appreciably as latitude increased across North America (i.e., northward, Fig. 4A, Supplementary Fig. S14, Table S7). The effect of longitude was variable: the coefficient estimates for longitude were negative for adenovirus and herpesvirus, positive for parvovirus and N. caninum, and approximately zero for distemper and T. gondii (Fig. 4B). Longitude was only a statistically significant predictor of herpesvirus exposure such that the probability of exposure to herpesvirus decreased as longitude increased across North America (i.e., eastward) - although statistically significant, the effect size of longitude on herpesvirus was relatively small as herpesvirus was common in our sampled study areas (mean seroprevalence $\sim 80 \%$ Fig. 3, S10). Pseudo-R ${ }^{2}$ values (Cragg-Uhler approximation, see SI) were lower for geographic models compared with complete models for the adenovirus, distemper, and herpesvirus; geographic model pseudo- $\mathrm{R}^{2}$ was higher for the $N$. caninum complete model; pseudo- $\mathrm{R}^{2}$ values were equal for both models for parvovirus and T. gondii. In general, the selected predictor variables accounted for a larger proportion of the variation in exposure than latitude and longitude.

The effect of habitat quality on pathogen exposure varied and tended to be small $(\beta<0$ adenovirus, distemper, herpesvirus, T. gondii; $\beta>0$ parvovirus, $N$. caninum); habitat quality was only considered a statistically significant predictor of canine distemper (Fig. 4C). Increasing human density was significantly and positively related to the 


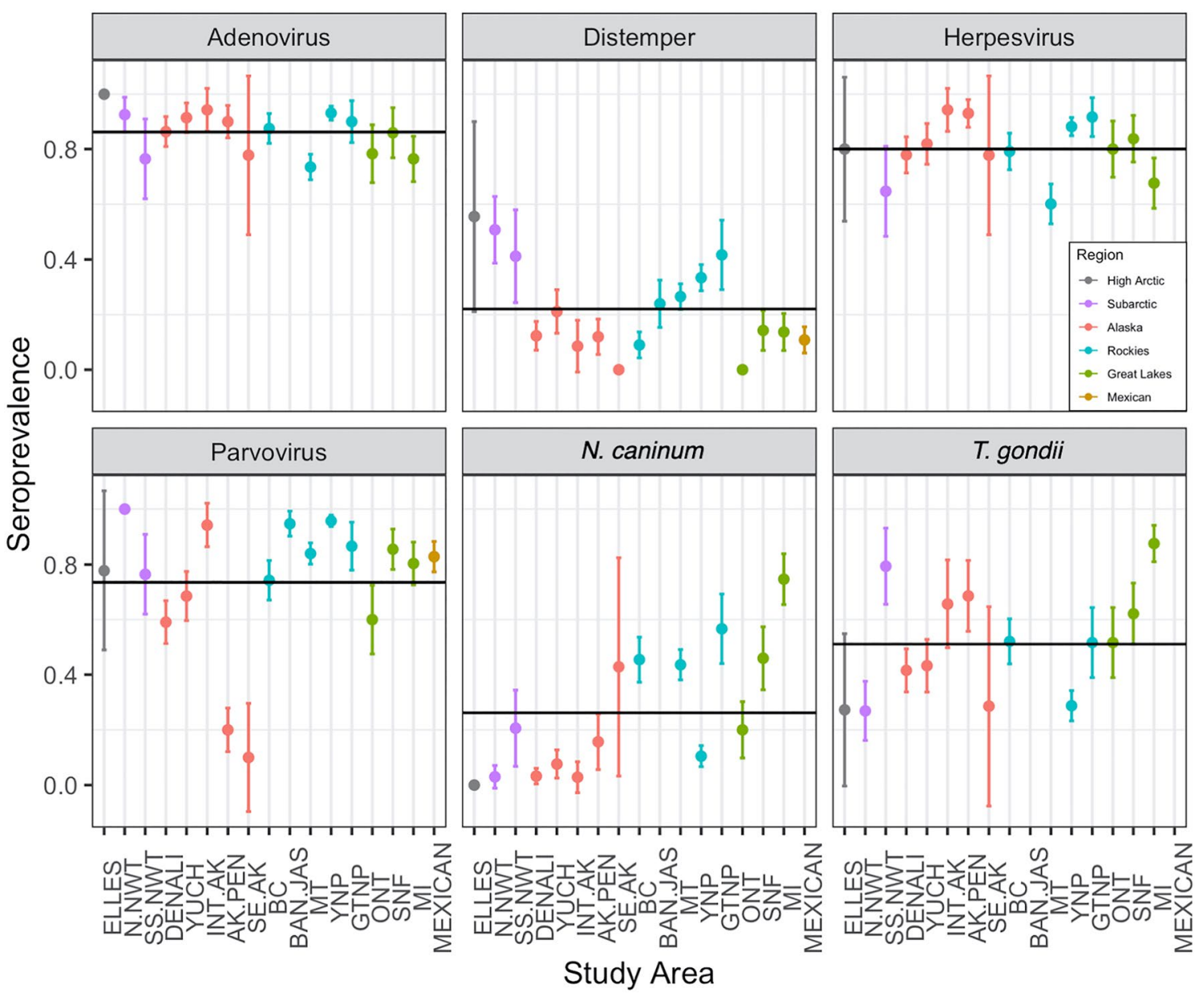

Figure 3. A panel plot displaying seroprevalence estimates, and $95 \%$ confidence intervals, for each pathogen tested from each study area ${ }^{39}$. Study areas are listed approximately north (left) to south (right) on the x-axis and grouped by region: High Arctic (gray), Subarctic (purple), Alaska (red), central Rocky Mountains (turquoise), Great Lakes (green), and Mexican (gold) (see Fig. 1 caption for study area abbreviations). The horizontal lines show the grand mean seroprevalence for each pathogen. Note that not all study areas were tested for each pathogen.

probability of pathogen exposure for all pathogens $(\beta>0, \mathrm{p} \leq 0.05$ except $T$. gondii; Fig. 4D). Human density had large effects on distemper, parvovirus, and N. caninum - for example, the probability a wolf was seropositive for distemper increased $68 \%$ over the human density range assessed (Supplementary Fig. S9). Similarly, wolf density was positively related to the probability of pathogen exposure for all pathogens $(\beta>0)$, except T. gondii $(\beta \sim 0)$, and was a statistically significant predictor of pathogen exposure for pathogens except parvovirus and T. gondii (Fig. 4E). The effect of pack size on probability of exposure was variable $(\beta<0$ N. caninum, T. gondii; $\beta>0$ adenovirus, herpesvirus, parvovirus; $\beta \sim 0$ distemper), but these effects were small and statistically insignificant (Fig. $4 \mathrm{~F}$ ). Contrary to our predictions, probability of pathogen exposure was invariant to coat color and sex such that effect sizes were small and statistically insignificant (Fig. $4 \mathrm{H}, \mathrm{G})$; the exception was that gray wolves had a slightly higher probability of exposure to N. caninum than black wolves. As expected, seroprevalence increased with age for all pathogens (Fig. 4I,J). See SI Model Results (Supplementary Table S7) for additional modeling outputs.

We performed a four-fold cross validation whereby 13 study areas were used as the training set and the remaining four study areas were used as the testing set (Supplementary Fig. S5, Table S6). Testing set RMSE values were higher than RMSE values from models built using the training set, indicating that predictive power was weaker than explanatory power, as expected ${ }^{72}$. This also suggests that model fit was not highly dependent on which study areas were used in the training or testing sets. Geographic models had marginally higher RMSE and lower AUC than complete models, indicating slightly poorer fit and classification power. Regardless of model, exposure to some pathogens was better explained than others (e.g., poorest fit for T. gondii, best fit for adenovirus and herpesvirus). RMSE values were fairly high across all models, meaning that there was a significant amount of variation in pathogen exposure that was unaccounted for-especially T. gondii. This was also evident in that random effects accounted for a notable portion of the variation in pathogen exposure (Fig. 5), and pseudo- $\mathrm{R}^{2}$ values were fairly low $(<0.4)$.

Models had moderate power to correctly classify an individual as positive or negative for pathogen exposure (mean training set AUC $=0.69$, mean testing set AUC $=0.67$ ). For pathogens other than T. gondii, AUC dropped, on average, $2-4 \%$ from training to testing sets when evaluating the same pathogen; the training set AUC was, 
(A)

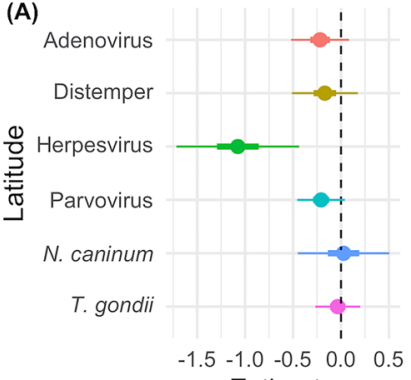

Estimate

(E)

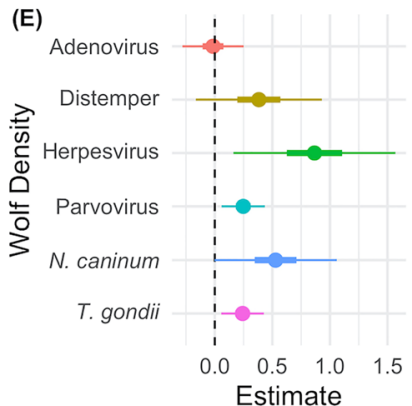

(I)

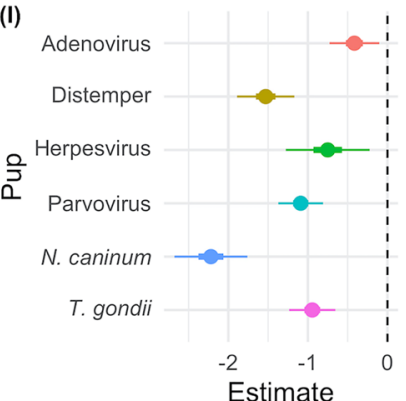

(B)

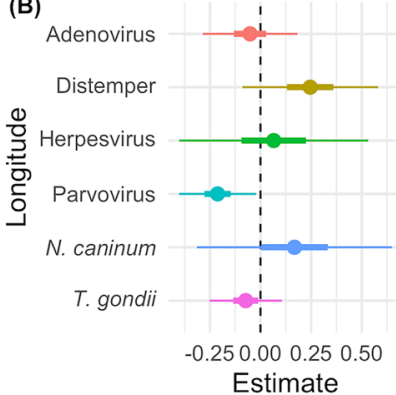

(F)
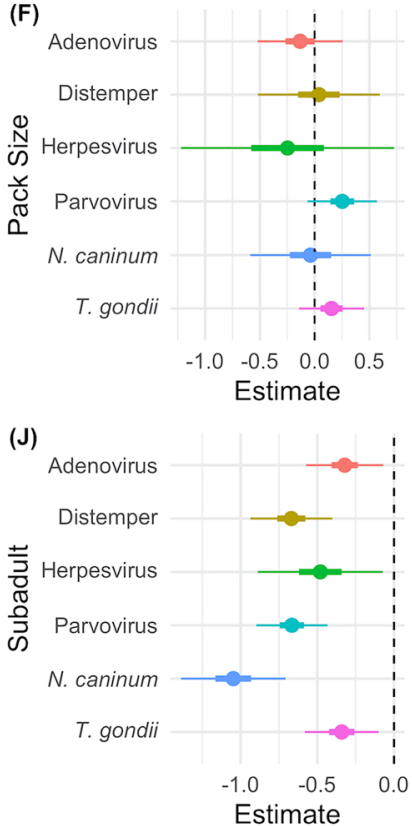

(C)

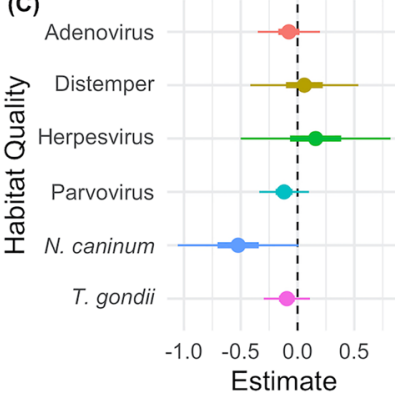

(G)

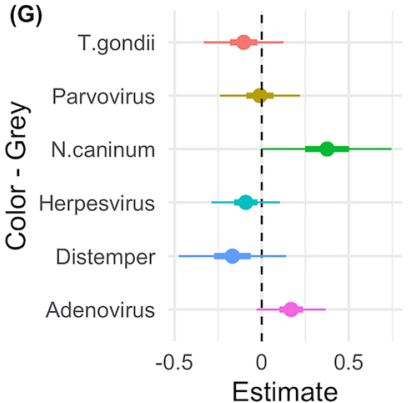

(D)

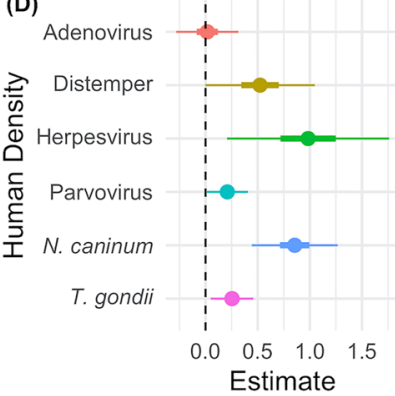

(H)

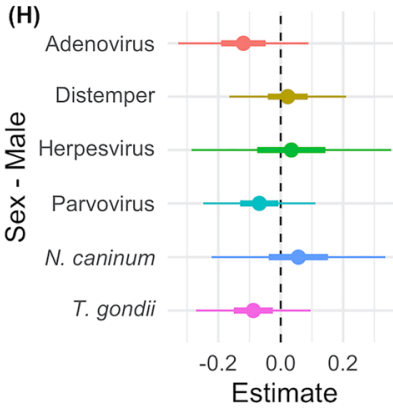

Figure 4. Coefficient estimates (log-odds) of the fixed effects in the (A,B) geographic and (C-J) complete models by pathogen (colors) ${ }^{39}$. Thick and thin lines are $50 \%$ and $95 \%$ confidence intervals, respectively. Categorical variables are interpreted as the effect of: $(\mathbf{G})$ gray wolves with respect to black, $(\mathbf{H})$ males with respect to females, and (I) pups and (J) subadults with respect to adults.

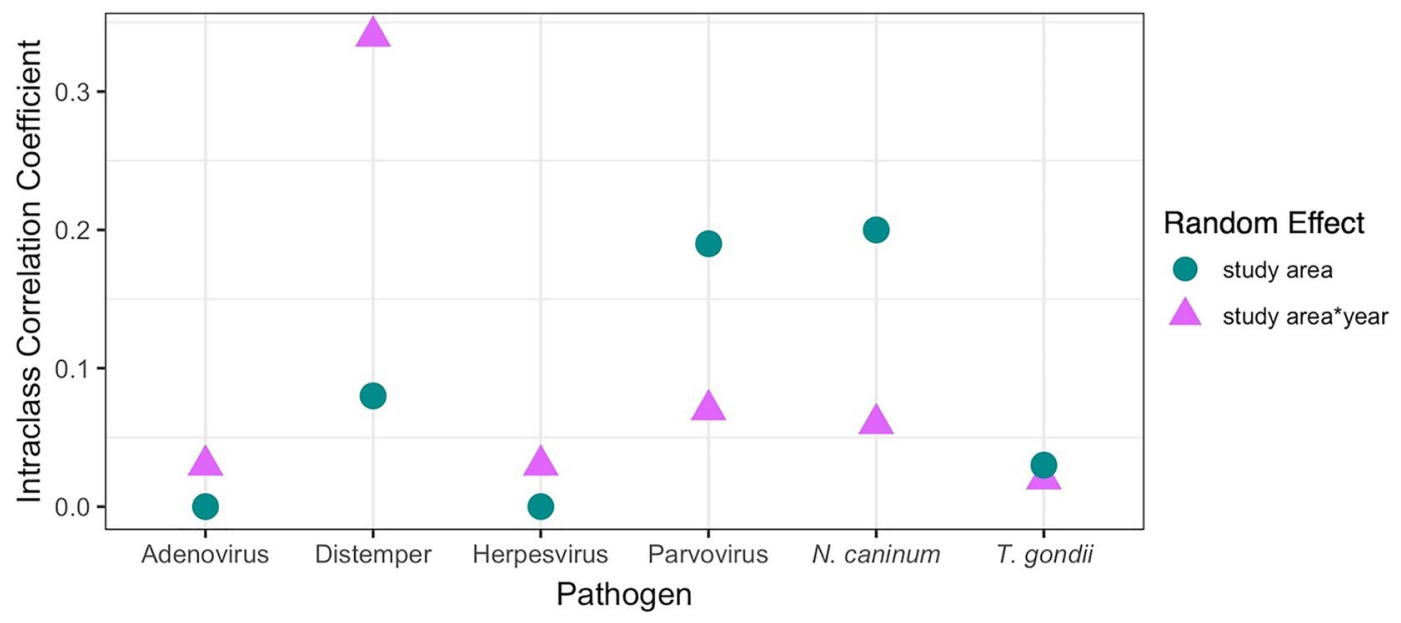

Figure 5. Intraclass correlation coefficient values for the random effects from the complete models: study area (teal circles) and study area ${ }^{*}$ ear (purple triangles) ${ }^{39}$. 
on average, about $4 \%$ higher using complete models compared with geographic models, and the testing set AUC improved 2.3\%. Complete models, therefore, provided modest improvements to the geographic models.

Random effects. Random effects (study area and study area*year) accounted for a notable portion of the deviance in exposure status (range $=0-33 \%$, mean $=9 \%$ ). We explicitly compared the random effects by calculating intraclass correlation coefficient, which describes the proportion of variance in exposure probability that the grouping accounts for (i.e., study area or study area ${ }^{*}$ ear, Fig. 5). The effect of study area and study area*year differed by pathogen, but we can generalize that: (1) study area was most important for N. caninum and parvovirus, (2) study area*year was most important for distemper virus due to its epizootic nature, (3) random effects were not very important for pathogens that were universally prevalent (e.g., adenovirus and herpesvirus), and (4) both study area and study area ${ }^{*}$ ear did not account for very much variation in T. gondii exposure, potentially because it was fairly common in all sampled study areas (Fig. 3). For example, in Yellowstone, the odds of distemper exposure differed up to tenfold among years (Supplementary Fig. S18A), whereas T. gondii exposure was stable (Supplementary Fig. S18B). Parvovirus exposure was most variable across study areas, but there was still some fluctuation within study areas. In other words, parasite exposure was more dependent on spatial dynamics whereas epizootic viruses were more dependent on temporal dynamics.

We can also draw conclusions from assessing the study area random intercepts, which provides a comparison to the baseline, or grand mean, probability of pathogen exposure across North American wolf populations (Supplementary Fig. S19, S20). The probability of contracting N. caninum increased significantly from north to south; T. gondii was more variable, and wolves from Michigan and South Slave Northwest Territories had particularly high odds of exposure. Epizootic viruses (i.e., parvovirus and distemper) had less predictable latitudinal trends, but Great Lakes and Alaska wolves generally had lower odds of exposure. Wolves in the central Rocky Mountains (except British Columbia) were more likely to be seropositive for both parvovirus and distemper, and South Slave Northwest Territories and Mexican wolves also had higher probability of distemper exposure. Adenovirus and herpesvirus antibodies were highly prevalent across all study areas sampled (often $>75 \%$ seroprevalence, Fig. 3), thus all intercept estimates hovered around the grand mean.

\section{Discussion}

Spatial variation in pathogen infections in wide-ranging hosts have been described by latitudinal gradients $^{5-7,11,12,73,74}$. While latitude may predict pathogen dynamics, it does not elucidate the underlying mechanisms. This is largely because necessary datasets to assess mechanisms of exposure are difficult to acquire across a species' geographic range. Our objectives were to describe the spatial variation in seroprevalence of gray wolves spanning the North American continent, identify which variables best predict pathogen exposure, and expand our understanding about the mechanisms driving pathogen dynamics. Specifically, we focused on the effect of latitude as a primary driver of spatial variation in seroprevalence. To this end, we compiled an expansive serological dataset that captures the natural variation in pathogen seroprevalence as well as variables at the ecosystem, population, and individual scales (Figs. 1,2). The effect size of latitude was greatest for N. caninum exposure, and compared with the other study areas, $N$. caninum seroprevalence trends most closely tracked latitude (Figs. 3, 4). Study areas in close proximity were more likely to be similar; for example, Great Lakes wolves had a lower probability of exposure for distemper and parvovirus, whereas wolves in the Arctic and central Rocky Mountains had higher probabilities. Our results highlight that individual host characteristics, as well as inherent features of ecosystems, determine pathogen exposure risk.

Human density was correlated with an increased probability of exposure of the four viruses of interest and $N$. caninum. Human density may be a proxy for density of unvaccinated dogs or synanthropic animals that act as reservoirs for infectious diseases that spill over into wolves ${ }^{52}$. Domestic dogs in Africa are the primary reservoir for canine distemper and rabies, and are responsible for major epizootics from these diseases in other wildlife species following spillover ${ }^{23,25,75,76}$. Across North America, we expect that dogs and synanthropic wildlife (e.g., raccoons, skunks, rodents) are important reservoirs for transmitting canine distemper, parvovirus, and T. gondii. Once spillover has occurred, wolf contact rate (i.e., density) must be high enough for wolf-wolf transmission. This might explain why we observed higher distemper and parvovirus seroprevalence in populations with both high human and wolf densities: Yellowstone, Grand Teton, and Banff and Jasper National Parks. However, dog and human densities may not always covary-for instance, dog density is high in areas where dog sledding is popular (Alaska, Northwest Territories), but human density is low. Additionally, some populations did not follow this rule and warrant further investigation, such as the South Slave region of the Northwest Territories that had low wolf, human, and carnivore density, yet high distemper seroprevalence, and Mexican wolves that displayed relatively high seroprevalence and risk of exposure despite low wolf density.

We predicted that study areas with larger pack sizes would have higher pathogen seroprevalence, which has been demonstrated in primates ${ }^{77,78}$. On the other hand, larger packs may aid in individual recovery from nonimmunizing, chronic infections such as N. caninum, similar to wolves with sarcoptic mange ${ }^{15}$. However, mean pack size was not an important predictor of exposure to any pathogen in our models. We suggest that any effect of pack size on exposure risk may have been obscured by averaging across groups.

We predicted that better quality habitats would be more speciose and thus multi-host pathogens would occur at higher prevalences ${ }^{79-81}$. Interestingly, our results demonstrate a weak negative correlation between habitat quality and exposure probability. Our habitat quality index may have been a poor proxy for habitat quality, or not representative of quality habitat for other competent hosts. In reality, understanding the dynamics of multi-host pathogens requires knowledge about host contact rates, transmission, and pathogen reservoirs.

We expected black wolves to have a higher probability of pathogen exposure, in particular, canine distemper virus. Mechanistically this could occur because black wolves have improved immune responses to respiratory 
pathogens, and heterozygote black wolves have higher survival rates than their gray counterparts, especially in years of canine distemper virus ${ }^{29-31,81,82}$. Thus if black wolves survived pathogen infections at a higher rate, there would be more seropositive black wolves than gray wolves. We found that wolves in western study areas experienced more frequent distemper outbreaks and had a high proportion of black wolves (>30\%, Fig. 2, Supplementary Fig. S2). Wolves in the Great Lakes region experienced reduced pressure from distemper, and accordingly, had a much lower proportion of black wolves ( $<5 \%$, Fig. 2, Supplementary Fig. S2). However, wolf phenotype in the Great Lakes may also be influenced by historical hybridization with eastern wolves (C. l. lycaon $)^{83}$. Still, coat color was not a significant predictor of exposure to any pathogen except $N$. caninum. This does not preclude a relationship between coat color and pathogen infections, and potentially suggests that pathogen pressure may predict coat color, which would reverse the response and predictor variable compared to our GLMMs.

Neospora caninum was the only pathogen we investigated that showed a strong latitudinal gradient in risk of pathogen exposure (Fig. 4) and mean seroprevalence (Fig. 3). We postulate that this corresponds to the proportion of white-tailed deer (Odocoileus virginianus) in the local wolf diets. The N. caninum cervid-canid lifecycle is well established ${ }^{84}$, and white-tailed deer are considered to be the $N$. caninum reservoir ${ }^{27,85}$. N. caninum has been detected at low levels in North American caribou (Rangifer tarandus), elk (Cervus canadensis), bison (Bison bison), mule deer (Odocoileus hemionus), and moose (Alces alces) ${ }^{27,86-89}$, but robust and widespread sampling is generally lacking. Based on our findings, it appears that the probability of $N$. caninum exposure varies with white-tailed deer consumption: higher in the Great Lakes region (mean seroprevalence 47\%) where wolves primarily consume white-tailed deer and moose, moderate in the central Rocky Mountains (mean seroprevalence $39 \%$ ) where wolves opportunistically consume deer, and uncommon in Alaska, the Northwest Territories, and Nunavut (mean seroprevalence 12\%) where white-tailed deer do not occur ${ }^{49,90-97}$. This supports the notion that white-tailed deer are the natural hosts for N. caninum, although livestock consumption may also play a role, and both should also be evaluated such as adding diet data or deer/livestock density into future models.

The complete models provided modest improvements to the geographic models in terms of model fit and predictive power, indicating that mechanistic variables described a greater proportion of the observed variation in pathogen exposure than geography alone. More importantly, this provides a stronger interpretation of the drivers of pathogen exposure. However, serological data and corresponding host metadata are logistically challenging to collect and compile, thus our results also suggest that, for some host-pathogen systems, information from adjacent wolf populations may provide decent insight into pathogen dynamics.

\section{Conclusion}

Elucidating the biogeographic patterns of pathogen exposure in a single host species across its distribution provides us with a deeper understanding of the mechanisms driving exposure, how these drivers predictably vary through space and time, and potential effects on host population dynamics or individual vital rates. We identified human density as a major driver of pathogen exposure at a continental scale. Anthropogenic environments create opportunities for aggregations of reservoir hosts and pathogen persistence, which in turn can affect wildlife-even wildlife that purposefully avoid human activity centers, like gray wolves ${ }^{63,98}$. Large-scale pathogen patterns have not been previously identified for the gray wolf, and here we show that regional rather than latitudinal patterns of seroprevalence were supported, with antibodies to viral pathogens more commonly identified among wolves in the Rocky Mountains whereas antibodies to parasites were more commonly identified among wolves in the Great Lakes region. This work builds upon previous studies and will hopefully serve as a catalyst for additional investigations into carnivore disease ecology, multi-host transmission dynamics, and biogeographic wildlife surveillance.

\section{Data accessibility}

All data and code are publicly available on the Dryad Repository https://doi.org/10.5061/dryad.5hqbzkh51.

Received: 27 October 2020; Accepted: 29 December 2020

Published online: 12 February 2021

\section{References}

1. Ferrari, M. J. et al. The dynamics of measles in sub-Saharan Africa. Nature 451, 679-684 (2008).

2. Hudson, P. J. et al. Trophic interactions and population growth rates: Describing patterns and identifying mechanisms. Philos. Trans. R. Soc. B Biol. Sci. 357, 1259-1271 (2002).

3. Thieltges, D. W., Ferguson, M. A. D., Jones, C. S., Leslie, R. \& Poulin, R. Biogeographical patterns of marine larval trematode parasites in two intermediate snail hosts in Europe. J. Biogeogr. 36, 1493-1501 (2009).

4. Bryan, H. M. et al. Seasonal and biogeographical patterns of gastrointestinal parasites in large carnivores: Wolves in a coastal archipelago. Parasitology 139, 781-790 (2012).

5. Hosseini, P. R., Dhondt, A. A. \& Dobson, A. Seasonality and wildlife disease: how seasonal birth, aggregation and variation in immunity affect the dynamics of Mycoplasma gallisepticum in house finches. Proc. R Soc. London Ser. B Biol. Sci. 271, 2569-2577 (2004).

6. Guernier, V., Hochberg, M. E. \& Guégan, J. F. Ecology drives the worldwide distribution of human diseases. PLoS Biol. 2, 740-746 (2004).

7. Nunn, C. L., Altizer, S. M., Sechrest, W. \& Cunningham, A. A. Latitudinal gradients of parasite species richness in primates. Divers. Distrib. 11, 249-256 (2005).

8. Merino, S. et al. Haematozoa in forest birds from southern Chile: Latitudinal gradients in prevalence and parasite lineage richness. Austral. Ecol. 33, 329-340 (2008).

9. Benejam, L., Alcaraz, C., Sasal, P., Simon-Levert, G. \& García-Berthou, E. Life history and parasites of the invasive mosquitofish (Gambusia holbrooki) along a latitudinal gradient. Biol. Invasions 11, 2265-2277 (2009).

10. Seabloom, E. W., Borer, E. T., Mitchell, C. E. \& Power, A. G. Viral diversity and prevalence gradients in North American Pacific Coast grasslands. Ecology 91, 721-732 (2010). 
11. Bonds, M. H., Dobson, A. P. \& Keenan, D. C. Disease ecology, biodiversity, and the latitudinal gradient in income. PLoS Biol. 10, e1001456 (2012).

12. Kriger, K. M., Pereoglou, F. \& Hero, J. M. Latitudinal variation in the prevalence and intensity of chytrid (Batrachochytrium dendrobatidis) infection in eastern Australia. Conserv. Biol. 21, 1280-1290 (2007).

13. Peterson, R. O., Thomas, N. J., Thurber, J. M., Vucetich, J. A. \& Waite, T. A. Population limitations and the wolves of Isle Royale. J. Mammal. 97, 828-841 (1998).

14. Almberg, E. S., Mech, L. D., Smith, D. W., Sheldon, J. W. \& Crabtree, R. L. A serological survey of infectious disease in Yellowstone National Park's canid community. PLoS ONE 4, e7042 (2009).

15. Almberg, E. S. et al. Social living mitigates the costs of a chronic illness in a cooperative carnivore. Ecol. Lett. 18, 660-667 (2015).

16. Brandell, E. E. et al. Infectious diseases in Yellowstone's Wolves. In Yellowstone Wolves: Science and Discovery in the World's First National Park (eds. Smith, D. W., Stahler, D. R. \& MacNulty, D. R.) 121-133 (The University of Chicago Press, 2020).

17. Watts, D. E. \& Benson, A. M. Prevalence of antibodies for selected canine pathogens among wolves (Canis lupus) from the Alaska Peninsula, USA. J. Wildl. Dis. 52, 506-515 (2016).

18. Carstensen, M. et al. A serosurvey of diseases of free-ranging gray wolves (Canis lupus) in Minnesota, USA. J. Wildl. Dis. 53, 459-471 (2017).

19. Anderson, R. M. \& May, R. M. Regulation and stability of host-parasite population interactions: I. Regulatory processes. J. Anim. Ecol. 47, 219-247 (1978).

20. Silbernagel, E. R., Skelton, N. K., Waldner, C. L. \& Bollinger, T. K. Interaction among deer in a chronic wasting disease endemic zone. J. Wildl. Manag. 75, 1453-1461 (2011).

21. Gehrt, S. D. Raccoons and allies. In Wild Mammals of North America: Biology, Management, and Conservation (eds. Feldhamer, G., Thompson, B. \& Chapman, J.) 611-633 (2003).

22. McFarlane, R., Sleigh, A. \& McMichael, T. Synanthropy of wild mammals as a determinant of emerging infectious diseases in the Asian-Australasian region. EcoHealth 9, 24-35 (2012).

23. Woodroffe, R. et al. Contact with domestic dogs increases pathogen exposure in endangered African wild dogs (Lycaon pictus). PLOS ONE 7, e30099 (2012).

24. Knobel, D. L., Butler, J. R., Lembo, T., Critchlow, R. \& Gompper, M. E. Dogs, disease, and wildlife. In Free-Ranging Dogs and Wildlife Conservation (ed. Gompper, M. E.) (Oxford University Press, Oxford, 2014).

25. Viana, M. et al. Dynamics of a morbillivirus at the domestic-wildlife interface: Canine distemper virus in domestic dogs and lions. Proc. Natl. Acad. Sci. 112, 1464-1469 (2015).

26. Bianco, A. et al. Two waves of canine distemper virus showing different spatio-temporal dynamics in Alpine wildlife (2006-2018). Infect. Genet. Evol. 84, 104359 (2020).

27. Dubey, J. P., Schares, G. \& Ortega-Mora, L. M. Epidemiology and control of neosporosis and Neospora caninum. Clin. Microbiol. Rev. 20, 323-367 (2007).

28. Anderson, T. M. et al. Molecular and evolutionary history of melanism in North American gray wolves. Science 323, 1339-1343 (2009).

29. Candille, S. I. et al. A $\beta$-defensin mutation causes black coat color in domestic dogs. Science 318, 1418-1423 (2007).

30. Coulson, T., Macnulty, D. R., Stahler, D. R., Wayne, R. K. \& Smith, D. W. Modeling effects of environmental change on wolf population dynamics, trait evolution, and life history. Science 334, 1275-1278 (2011)

31. Hedrick, P. W., Stahler, D. R. \& Dekker, D. Heterozygote advantage in a finite population: Black color in wolves. J. Hered. 105, 457-465 (2014).

32. Altizer, S., Davis, A. K., Cook, K. C. \& Cherry, J. J. Age, sex, and season affect the risk of mycoplasmal conjunctivitis in a southeastern house finch population. Can. J. Zool. 82, 755-763 (2004).

33. Biek, R. et al. Factors associated with pathogen seroprevalence and infection in Rocky Mountains cougars. J. Wildl. Dis. 42, 606-615 (2006).

34. Härkönen, T., Harding, K., Rasmussen, T. D., Teilmann, J. \& Dietz, R. Age- and sex-specific mortality patterns in an emerging wildlife epidemic: The phocine distemper in European harbour seals. PLoS ONE 2, e887 (2007).

35. Guerra-Silveira, F. \& Abad-Franch, F. Sex bias in infectious disease epidemiology: Patterns and processes. PLoS ONE 8, e62390 (2013).

36. McDonald, J. L., Smith, G. C., McDonald, R. A., Delahay, R. J. \& Hodgson, D. Mortality trajectory analysis reveals the drivers of sex-specific epidemiology in natural wildlife-disease interactions. Proc. R. Soc. B Biol. Sci. 281, 20140526 (2014).

37. Williams, E. S. \& Barker, I. K. (eds) Infectious Diseases of Wild Mammals (Wiley, New York, 2001).

38. USGS. North America Political Boundaries. (2006). Available at: https://www.sciencebase.gov/catalog/item/4fb555ebe4b04cb $937751 \mathrm{db} 9$.

39. Justice-Allen, A. \& Clement, M. J. Effect of canine parvovirus and canine distemper virus on the Mexican wolf (Canis lupus baileyi) population in the USA. J. Wildl. Dis. 55, 682-688 (2019).

40. Nelson, B. et al. Prevalence of antibodies to canine parvovirus and distemper virus in wolves in the Canadian Rocky Mountains. J. Wildl. Dis. 48, 68-76 (2012).

41. R Core Team. R: A Language and Environment for Statistical Computing (R Foundation for Statistical Computing). (2019 v3.6.3). Available at: https://www.R-project.org.

42. Bates, D., Maechler, M., Bolker, B. \& Walker, S. Fitting linear mixed-effects models using lme4. J. Stat. Softw. 67, 1-48 (2015).

43. Gelman, A. \& Loken, E. The garden of forking paths: Why multiple comparisons can be a problem, even when there is no "fishing expedition" or "p-hacking" and the research hypothesis was posited ahead of time. Psychol. Bull. 140, 1272-1280 (2013).

44. Fuller, T. K. \& Murray, D. L. Biological and logistical explanations of variation in wolf population density. Anim. Conserv. 1, 153-157 (1998).

45. Fuller, T. K. \& Sievert, P. R. Carnivore demography and the consequences of changes in prey availability. In Conservation biology series - Cambridge 163-178 (2001).

46. MacNulty, D. R., Tallian, A., Stahler, D. R. \& Smith, D. W. Influence of group size on the success of wolves hunting bison. PLoS ONE 9, 1-8 (2014).

47. Barber-Meyer, S. M., Mech, L. D., Newton, W. E. \& Borg, B. L. Differential wolf-pack-size persistence and the role of risk when hunting dangerous prey. Behaviour 153, 1473-1487 (2016).

48. Gipson, P. S., Ballard, W. B., Nowak, R. M. \& Mech, L. D. Accuracy and precision of estimating age of gray wolves by tooth wear. J. Wildl. Manag. 64, $752(2000)$

49. Fuller, T. K., Mech, L. D. \& Cochrane, J. F. Wolf population dynamics. In Wolves: Behavior, Ecology, and Conservation (eds Mech, L. D. \& Boitani, L.) 161-191 (University of Chicago Press, Chicago, 2003).

50. Jimenez, M. D. et al. Wolf dispersal in the Rocky Mountains, Western United States: 1993-2008. J. Wildl. Manag. 81, 581-592 (2017).

51. NASA Socioeconomic Data and Applications Center. Gridded Population of the World (GPW), v4. EarthData (2015). Available at: https://sedac.ciesin.columbia.edu/data/set/gpw-v4-population-count-rev11/data-download.

52. Millán, J. et al. Patterns of exposure of Iberian wolves (Canis lupus) to canine viruses in human-dominated landscapes. EcoHealth 13, 123-134 (2016). 
53. North American Land Change Monitoring System 30m, 2010-2015 (Landsat). Commission of Environmental Cooperation (2015). Available at: http://www.cec.org/north-american-land-change-monitoring-system/.

54. USGS EROS Archive-Digital Elevation-Global 30 Arc-Second Elevation (GTOPO30). Earth Resources Observation and Science (EROS) Center (1996).

55. Hesselbarth, M. H. K., Sciaini, M., With, K. A., Wiegand, K. \& Nowosad, J. landscapemetrics: an open-source R tool to calculate landscape metrics. Ecography 42, 1648-1657 (2019).

56. Poole, K. G., Wakelyn, L. A. \& Nicklen, P. N. Habitat selection by lynx in the Northwest Territories. Can. J. Zool. 74, 845-850 (1996).

57. Nielsen, S. E., Boyce, M. S., Stenhouse, G. B. \& Munro, R. H. M. Modeling grizzly bear habitats in the yellowhead ecosystem of Alberta: Taking autocorrelation seriously. Ursus 13, 45-56 (2001).

58. Arjo, W. M. \& Pletscher, D. H. Coyote and wolf habitat use in northwestern Montana. Northwest Sci. 78, 24-32 (2004).

59. Oakleaf, J. K. et al. Habitat selection by recolonizing wolves in the northern Rocky Mountains of the United States. J. Wildl. Manag. 70, 554-563 (2006).

60. Hebblewhite, M. \& Merrill, E. Modelling wildlife-human relationships for social species with mixed-effects resource selection models. J. Appl. Ecol. 45, 834-844 (2008).

61. Roever, C. L., Boyce, M. S. \& Stenhouse, G. B. Grizzly bears and forestry II: Grizzly bear habitat selection and conflicts with road placement. For. Ecol. Manag. 256, 1262-1269 (2008).

62. Houle, M., Fortin, D., Dussault, C., Courtois, R. \& Ouellet, J. P. Cumulative effects of forestry on habitat use by gray wolf (Canis lupus) in the boreal forest. Landsc. Ecol. 25, 419-433 (2010).

63. Mayor, S. J., Schneider, D. C., Schaefer, J. A. \& Mahoney, S. P. Habitat selection at multiple scales. Ecoscience 16, 238-247 (2009).

64. Milakovic, B. et al. Habitat selection by a focal predator (Canis lupus) in a multiprey ecosystem of the northern Rockies. J. Mammal. 92, 568-582 (2011).

65. Kittle, A. M. et al. Wolves adapt territory size, not pack size to local habitat quality. J. Anim. Ecol. 84, 1177-1186 (2015).

66. Kittle, A. M. et al. Landscape-level wolf space use is correlated with prey abundance, ease of mobility, and the distribution of prey habitat. Ecosphere 8, e01783 (2017).

67. Morin, S. J., Bowman, J., Marrotte, R. R. \& Fortin, M. J. Fine-scale habitat selection by sympatric Canada lynx and bobcat. Ecol. Evol. 10, 9396-9409 (2020).

68. O'Neil, S. T., Vucetich, J. A., Beyer, D. E., Hoy, S. R. \& Bump, J. K. Territoriality drives preemptive habitat selection in recovering wolves: Implications for carnivore conservation. J. Anim. Ecol. 89, 1433-1447 (2020).

69. Gelman, A. \& Hill, J. Data analysis using regression and multilevel/hierarchical models (Cambridge University Press, 2007).

70. Menard, S. Standards for standardized logistic regression coefficients. Soc. Forces 89, 1409-1428 (2011).

71. Hosmer, D. W. \& Lemeshow, S. Applied Logistic Regression (Wiley, New York, 2000).

72. Hastie, T., Tibshirani, R. \& Friedman, J. The Elements of Statistical Learning: Data Mining, Inference, and Prediction (Springer, Berlin, 2009).

73. Finkelman, B. S. et al. Global patterns in seasonal activity of influenza A/H3N2, A/H1N1, and B from 1997 to 2005: Viral coexistence and latitudinal gradients. PLoS ONE 2, e1296 (2007).

74. Nguyen, D. et al. Fungal disease incidence along tree diversity gradients depends on latitude in European forests. Ecol. Evol. 6, 2426-2438 (2016).

75. Rhodes, C. J., Atkinson, R. P. D., Anderson, R. M. \& Macdonald, D. W. Rabies in Zimbabwe: reservoir dogs and the implications for disease control. Philos. Trans. R Soc. Lond. Ser. B Biol. Sci. 353, 999-1010 (1998).

76. Lembo, T. et al. Exploring reservoir dynamics: A case study of rabies in the Serengeti ecosystem. J. Appl. Ecol. 45, 1246-1257 (2008).

77. Nunn, C. L., Altizer, S., Jones, K. E. \& Sechrest, W. Comparative tests of parasite species richness in primates. Am. Nat. 162, 597-614 (2003).

78. Nunn, C. L. \& Heymann, E. W. Malaria infection and host behavior: A comparative study of Neotropical primates Malaria infection and host behavior. Behav. Ecol. Sociobiol. 59, 30-37 (2005).

79. Begon, M., Bowers, R. G., Kadianakis, N. \& Hodgkinson, D. E. Disease and community structure: the importance of host selfregulation in a host-host-pathogen model. Am. Nat. 139, 1131-1150 (1992).

80. Power, A. G. \& Mitchell, C. E. Pathogen spillover in disease epidemics. Am. Nat. 164, S79-S89 (2004).

81. Keesing, F., Holt, R. D. \& Ostfeld, R. S. Effects of species diversity on disease risk. Ecol. Lett. 9, 485-498 (2006).

82. Schweizer, R. M. et al. Natural selection and origin of a melanistic allele in North American gray wolves. Mol. Biol. Evol. 35 , $1190-1209$ (2018).

83. Wilson, P. J., Grewal, S. K., Mallory, F. F. \& White, B. N. Genetic characterization of hybrid wolves across Ontario. J. Hered. 100, S80-S89 (2009).

84. Gondim, L. F. P. et al. Transmission of Neospora caninum between wild and domestic animals. J. Parasitol. 90, 1361-1365 (2004).

85. Dubey, J. P. et al. Seroprevalence of Neospora caninum and Toxoplasma gondii antibodies in white-tailed deer (Odocoileus virginianus) from Iowa and Minnesota using four serologic tests. Vet. Parasitol. 161, 330-334 (2009).

86. Stieve, E., Beckmen, K., Kania, S. A., Widner, A. \& Patton, S. Neospora caninum and Toxoplasma gondii antibody prevalence in Alaska wildlife. J. Wildl. Dis. 46, 348-355 (2010).

87. Pruvot, M., Hutchins, W. \& Orsel, K. Statistical evaluation of a commercial Neospora caninum competitive ELISA in the absence of a gold standard: Application to wild elk (Cervus elaphus) in Alberta. Parasitol. Res. 113, 2899-2905 (2014).

88. Bondo, K. J. et al. Health survey of boreal caribou (Rangifer tarandus caribou) in northeastern British Columbia, Canada. J. Wildl. Dis. 55, 544-562 (2019).

89. Donahoe, S. L., Lindsay, S. A., Krockenberger, M., Phalen, D. \& Šlapeta, J. A review of neosporosis and pathologic findings of Neospora caninum infection in wildlife. Int. J. Parasitol. Parasites Wildl. 4, 216-238 (2015).

90. Huggard, D. J. Prey selectivity of wolves in Banff National Park I. Prey species. Can. J. Zool. 71, 130-139 (1993).

91. Hebblewhite, M., Paquet, P. C., Pletscher, D. H., Lessard, R. B. \& Callaghan, C. J. Development and application of a ratio estimator to estimate wolf kill rates and variance in a multiple-prey system. Wildl. Soc. Bull. 31, 933-946 (2003).

92. Adams, L. G. et al. Are inland wolf-ungulate systems influenced by marine subsidies of Pacific salmon?. Ecol. Appl. 20, 251-262 (2010).

93. Latham, A. D. M., Latham, M. C., McCutchen, N. A. \& Boutin, S. Invading white-tailed deer change wolf-caribou dynamics in northeastern Alberta. J. Wildl. Manag. 75, 204-212 (2011).

94. Metz, M. C., Smith, D. W., Vucetich, J. A., Stahler, D. R. \& Peterson, R. O. Seasonal patterns of predation for gray wolves in the multi-prey system of Yellowstone National Park. J. Anim. Ecol. 81, 553-563 (2012).

95. Merkle, J. A., Polfus, J. L., Derbridge, J. J. \& Heinemeyer, K. S. Dietary niche partitioning among black bears, grizzly bears and wolves in a multi-prey ecosystem. Can. J. Zool. 95, 663-671 (2017).

96. Gable, T. D., Windels, S. K., Bruggink, J. G. \& Barber-Meyer, S. M. Weekly summer diet of gray wolves (Canis lupus) in northeastern Minnesota. Am. Midl. Nat. 179, 15-27 (2018).

97. O’Donovan, S. A., Budge, S. M., Hobson, K. A., Kelly, A. P. \& Derocher, A. E. Intrapopulation variability in wolf diet revealed using a combined stable isotope and fatty acid approach. Ecosphere 9 , e02420 (2018).

98. Whittington, J., St. Clair, C. C. \& Mercer, G. Spatial responses of wolves to roads and trails in mountain valleys. Ecol. Appl. 15, 543-553 (2005). 


\section{Acknowledgements}

We thank the wildlife professionals that contributed wolf sera, serology data, and metadata to this project: Erin Stahler, L. David Mech, Dean Beyer, Erin Largent, Susan Dicks, John Oakleaf, the Mexican Wolf Project, Lindsey Dreese, Brent Patterson, Emily Almberg, Montana Fish Wildlife and Parks, Shari Willmott, and the countless unlisted biologists that collected these samples and data through the decades. Financial support includes: E.E.B. and P.J.H. endowment from Verne Willaman; E.E.B. and P.C.C. U.S. Geological Survey (Grant G17AC00427); D.W.S., D.R.S., and D.R.M. NSF LTREB grant DEB-1245373 and many donors to Yellowstone Forever, especially Annie and Bob Graham and Valerie Gates; M.H. Parks Canada and NSF LTREB award 1556248; G.R. PittmanRobertson Federal Aid in Wildlife Restoration Program and the State of Alaska general funds; K.B. Federal Aid in Support of Wildlife Restoration and Alaska Dept. of Fish and Game; M.A. and H.S. British Columbia Ministry of Forests, Lands, Natural Resource Operations and Rural Development, Habitat Conservation Trust Foundation, Forest Enhancement Society of British Columbia; D.R.M and M.A. Polar Continental Shelf Project and National Geographic Society; M.L.J.G. the Office of the Director, National Institutes of Health under award number NIH T32OD010993; T.W. Ontario Ministry of Natural Resources and Forestry; B.L.B. National Park Service; A.K. GNWT Environmental Stewardship Fund. The content is solely the responsibility of the authors and does not necessarily represent the official views of the National Institutes of Health. Any use of trade, product, or firm names is for descriptive purposes only and does not imply endorsement by the U.S. Government.

\section{Author contributions}

E.E.B., P.C.C., D.W.S., and P.J.H. formulated the hypotheses and designed the project. E.E.B. conducted the data collection, performed all analyses, and wrote the first draft of the manuscript. All authors provided samples, metadata, and contributed substantially to manuscript development and revisions.

\section{Additional information \\ Supplementary Information The online version contains supplementary material available at https://doi.org/ 10.1038/s41598-021-81192-w.}

Correspondence and requests for materials should be addressed to E.E.B.

Reprints and permissions information is available at www.nature.com/reprints.

Publisher's note Springer Nature remains neutral with regard to jurisdictional claims in published maps and institutional affiliations.

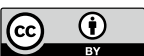

Open Access This article is licensed under a Creative Commons Attribution 4.0 International License, which permits use, sharing, adaptation, distribution and reproduction in any medium or format, as long as you give appropriate credit to the original author(s) and the source, provide a link to the Creative Commons licence, and indicate if changes were made. The images or other third party material in this article are included in the article's Creative Commons licence, unless indicated otherwise in a credit line to the material. If material is not included in the article's Creative Commons licence and your intended use is not permitted by statutory regulation or exceeds the permitted use, you will need to obtain permission directly from the copyright holder. To view a copy of this licence, visit http://creativecommons.org/licenses/by/4.0/.

(C) The Author(s) 2021, corrected publication 2021 